\title{
Evaluation of Drug Induced Liver Injury in Tuberculosis and Hepatitis Coinfection by Liver Fibrosis Index Score
}

\author{
Alkady OA $^{1 *}$, Yousef LY², Elkady AA ${ }^{3}$ and Elkady \\ AA $^{4}$ \\ ${ }^{1}$ Department of Chest Diseases and Tuberculosis, Sohag \\ University, Egypt \\ ${ }^{2}$ Department of Clinical Pathology, Sohag University, \\ Egypt \\ ${ }^{3}$ Department of Clinical Pathology, South Valley \\ University, Egypt \\ ${ }^{4}$ Department of Medical Microbiology and Immunology, \\ Assiut University, Egypt \\ *Corresponding author: Alkady OA, Department of \\ Chest Diseases and Tuberculosis, Faculty of Medicine, \\ Sohag University, Sohag, Egypt
}

Received: May 26, 2017; Accepted: J une 19, 2017; Published: July 05, 2017

\begin{abstract}
Background: Egypt has high Tuberculosis (TB), Hepatitis C (HCV) prevalence and intermediate Hepatitis B (HBV) prevalence with unclear Dug Induced liver injury (DILI) risk in chronic viral hepatitis patients.

Objective: To evaluate DILI incidence in tuberculous patients suffered from viral hepatitis co-infection compared to non hepatitis patients.

Methods: Newly diagnosed pulmonary TB patients under TB therapy were evaluated none invasively for DILI before and after treatment by liver function tests and liver fibrosis index (FIB-4 index).

Results: 195 tuberculous patients, age (19-61) years old. Of those, $62 \%$ (non hepatitis) were control, 31\% HCV, $5 \% \mathrm{HBV}, 2 \%$ were both (HB-C). Average baseline fibrosis indices in groups respectively were $0.81,1.41,0.70$, and 1.47 . Overall DILI respectively was $7 \%, 31 \%, 30 \%, 75 \%$. FIB-4 index was significantly increased after treatment in all groups with significant difference between control and $(\mathrm{HCV})$ group $(\mathrm{p}=0.04)$. The number of patients with FIB-4 index above 1.45 was $12 \%, 43 \%, 50 \%, 100 \%$ of all groups respectively with statistically significant difference in time lag to develop hepatotoxicity.
\end{abstract}

Conclusion: HCV, HBV, HB-C increases DILI risk after anti TB therapy. Meticulous follow up is advised. FBI-4 is a promising tool for liver damage evaluation. More studies are required to validate FIB-4 score.

Keywords: Tuberculosis; Drug induced liver injury; Liver fibrosis index

\section{Abbreviations}

TB: Tuberculosis; HBV: Hepatitis B Virus; HCV: Hepatitis C Virus; DILI: Drug Induced Liver Injury; FIB4- index: Liver Fibrosis Index Score

\section{Introduction}

Tuberculosis (TB) is a major global infectious disease caused by mycobacterium tuberculosis. It affects millions of people each year. In 2015 was ranking above HIV/AIDS as one of the leading causes of death from an infectious disease [1]. In Egypt, TB is considered the third most important public health problem after schistosomiasis and hepatitis C. WHO defined TB estimated rate in 2015 was 15 per 100,000 patients in Egypt [2].

Standard four-drug anti-TB therapy for active disease is associated with many side effects. Drug Induced liver injury (DILI) is the most dangerous. Majority of the reports have used an elevated alanine (ALT) or aspartate transaminase (AST) of 3 times upper limit of normal range (ULN) with symptoms (abdominal pain, nausea, vomiting, unexplained fatigue or jaundice) attributable to liver injury or 5 times ULN of ALT or AST without symptoms to define hepatotoxicity. Drug induced liver injury (DILI) accounts for 5\% mortality rate [3]. It can be caused by all anti TB medications and it's incidence during standard anti-TB treatment ranges from $2 \%$ to $28 \%$ depending on the definition of hepatotoxicity and the population studied $[4,5]$. When patients develop DILI, additional modes of anti-
TB treatment are used. Once DILI occurs, all anti-TB drugs should be withheld until a complete resolution of the hepatotoxicity is accomplished [6]. Among the anti-TB agents, isoniazid (INH) is the primary drug which induces hepatotoxicity in TB patients with DILI. On the other hand, one recent report proved that rifampicin (RF) high plasma levels compared to control group, independently predicted subsequent development of DIH [7]. Reported risk factors for development of DILI during anti TB treatment were female gender, advanced age, alcohol abuse, malnutrition, underlying chronic liver disease [8].

Hepatitis $\mathrm{C}$ virus (HCV) is a serious global health problem. WHO estimates that $3 \%$ of the world's population is infected with $\mathrm{HCV}$ and that more than 170 million chronic carriers are at risk of developing liver cirrhosis and/or liver cancer [9]. In Egypt, chronic hepatitis C virus (HCV) infection is a major cause of liver cirrhosis and liver cancer [10]. Hepatitis B is also one of the major health problems. In 2010 and 2014 resolutions of the World Health Assembly, have ranked $\mathrm{HBV}$ as the 15th cause of death in all cause global mortality [11]. Some recent studies have suggested that HCV infection is a significant risk factor for developing either DILI or transient liver dysfunction during anti-TB treatment $[12,13]$.

The aim of the study is to evaluate the incidence of drug induced liver injury in tuberculous patients who suffered from viral hepatitis co-infection compared to non hepatitis infected patients. DILI will be evaluated none invasively. 
Table 1: Demographic, risk factors and base line laboratory tests.

\begin{tabular}{|c|c|c|c|c|c|}
\hline & $\begin{array}{c}\text { Control } \\
n=120(62)\end{array}$ & $\begin{array}{l}\text { HCV } \\
n=61(31)\end{array}$ & $\begin{array}{c}\text { H B V } \\
n=10(5)\end{array}$ & $\begin{array}{l}H B+C \\
n=4(2)\end{array}$ & $P$ value \\
\hline Age & $34 \pm 12.7$ & $38.2 \pm 9.7$ & $32.6 \pm 8.2$ & $42.6 \pm 4.6$ & NS \\
\hline $\begin{array}{l}M \\
F\end{array}$ & $\begin{array}{l}68(57) \\
52(43)\end{array}$ & $\begin{array}{l}46(75) \\
15(25)\end{array}$ & $\begin{array}{l}6(60) \\
4(40)\end{array}$ & $\begin{array}{l}3(75) \\
1(25)\end{array}$ & $\begin{array}{l}\text { NS } \\
\text { NS }\end{array}$ \\
\hline Smoking & $85(70)$ & $47(77)$ & $6(60)$ & $3(75)$ & NS \\
\hline Alcohol & $10(8)$ & $6(10)$ & $4(40)$ & $2(50)$ & NS \\
\hline IV drug abuse & $6(5)$ & $5(8)$ & $3(30)$ & $1(25)$ & NS \\
\hline ALT & $28.8+11.2$ & $38.6+5.4$ & $29.2+6.3$ & $33.4+6$ & NS \\
\hline AST & $25.6+13$ & $34.7+4.6$ & $31.2+8.2$ & $36.4+6.1$ & NS \\
\hline Platelets & $260.25+112$ & $110.6+95$ & $220.8+101$ & $255.25+100$ & $\begin{array}{l}0.05 \\
0.02\end{array}$ \\
\hline $\mathrm{AL} \mathrm{Ph}$ & $53.5+18.6$ & $48.5+12.9$ & $56.8+11.7$ & $51.2+4$ & NS \\
\hline Bilirubin & $1.1+0.98$ & $1.6+1$ & $1.3+0.9$ & $1.2+1$ & NS \\
\hline FIB4 & $\begin{array}{c}0.43-1.55 \\
{[0.81]}\end{array}$ & $\begin{array}{c}0.45-3.02 \\
{[1.42]}\end{array}$ & $\begin{array}{c}0.37-96 \\
{[0.70]}\end{array}$ & $\begin{array}{c}1.22-1.62 \\
{[1.47]}\end{array}$ & $\begin{array}{l}0.2 \\
0.3\end{array}$ \\
\hline
\end{tabular}

HCV: Hepatitis C Virus; HBV: Hepatitis B Virus; ALT (U/L): Alanine Aminotransferase; AST (U/L): Aspartate Aminotransferase; ALP: Alkaline Phosphatase Albumin in $\mathrm{mg} / \mathrm{dl}$, bilirubin in $\mathrm{mg} / \mathrm{dl}$, FIB4 liver fibrosis index.

Number between ( ) are percentage(\%) and those between [ ] are average.

- The difference between control and HCV group.

* The difference between HCV and HBV group.

\section{Patients and Methods}

This study included newly diagnosed pulmonary TB patients who were enrolled at the department of chest diseases and tuberculosis, Sohag faculty of medicine, Sohag University, Egypt, in the period between January 2013 to December 2014. Institutional research ethics review Board has approved the study and patient's consent for the study was obtained from entire patients.

Patients who suffered from symptoms suggestive of TB such as cough, weight loss, night sweat, abnormal chest $\mathrm{x}$ ray findings, Acid-fast Bacilli (AFB) smear microscopy was performed using the Ziehl Neelson staining method. Culture was performed using solid (Lowenstein-Jensen) and liquid (MGIT BACTEC 960) media using standard methodologies $[14,15]$.

Exclusion criteria of the study were children $>16$ years and extrapulmonary $\mathrm{TB}$, miliary $\mathrm{TB}$, acute active hepatitis at time of diagnosis and decompensated liver cirrhosis or patients with liver malignancy. The treatment regimen was done according to WHO guidelines for management of TB $4^{\text {th }}$ edition that consisted of intensive therapy regimen for newly diagnosed TB. It consisted of a full 6 months treatment starting by 2 months of the following isoniazid, rifampicin, pyrazinamide, ethambutol followed by 4 months regimen of isoniazid and rifampicin [16].

The data collected from patient's medical records included: socio-demographic data (age, sex, alcohol consumption, smoking drug abuse), features of symptomatic hepatotoxicity (such as fatigue, loss of appetite, nausea, vomiting, right hypochondrial pain/ tenderness, fever, and jaundice), pulmonary or extrapulmonary TB, laboratory data including alanine transaminase ((IU/L), aspartate transaminase (IU/L), total bilirubin $(\mu \mathrm{mol} / \mathrm{L})$, total serum protein and albumin $(\mathrm{g} / \mathrm{L})$, hepatitis B surface antigen (HBsAg), and HCV antibody (anti-HCV),platelets counts and calculated liver fibrosis index FIB4 and cutline of FIB4 $[17,18]$. The FIB-4 index is calculated using the formula: FIB-4=Age (years) $\times$ AST $(\mathrm{U} / \mathrm{L}) /\left[\mathrm{PLT}\left(10^{9} / \mathrm{L}\right)\right.$ $\left.\times \operatorname{ALT}^{1 / 2}(\mathrm{U} / \mathrm{L})\right]$.

Liver functions tests were followed up on monthly basis. At the baseline visit, serum sample was collected and tested for HIV, Hepatitis B surface antigen and hepatitis B core antibody (HBsAg by the Auszyme Monoclonal and Corzyme assays (Abbott Laboratories, Abbott Park, IL, USA) and for HCV (HCV-Ab) by Ortho HCV Version 3.0 ELISA (Ortho Diagnostics Systems, Raritan, NJ, USA). HBV, HCV virus DNA-PCR detection was not done. Patients with symptoms suggestive of hepatitis or with an elevated ALT more than twice the upper limit of normal were referred to hepatologist for specific management but the patients didn't receive liver protective drugs. Abdominal ultrasound exam was done and medical treatment was carried out during this stage and the offending anti TB treatment was replaced by non hepatotoxic medication and resumption of classic regimen was obtained serially when liver functions tests returned to the base line or normalized. Rifampicin was first reintroduced at progressively increasing dose then isoniazid. The regimen included rifampicin, isoniazide and ethambutol without pyrazinamide.

\section{Results}

Medical records showed that 361 patients were diagnosed with TB. one hundred sixty six patients were excluded from the study, 102 were children, 44 patients had extra-pulmonary TB, 9 had acute active hepatitis at time of diagnosis of pulmonary TB, 6 had end-stage liver disease with jaundice and ascites, 5 patients has liver malignancy, 3 of them had hepatocellular carcinoma and 2 had metastatic liver disease from colorectal cancer and neuroendocrine tumor of pancreas. The study included 195 patients who were recently diagnosed with pulmonary TB and antituberculous therapy was commenced. Their age ranged from 19 to 61 years old with average of 36.7 years, males constituted $63 \%$ of study population $(n=123)$ while as $37 \%$ were females $(n=72)$. 
Table 2: Hepatotoxicity after commencement of antituberculous treatment in the 4 groups.

\begin{tabular}{|c|c|c|c|c|c|}
\hline & $\begin{array}{c}\text { Control } \\
n=120(62)^{*}\end{array}$ & $\begin{array}{c}\text { HCV } \\
n=61(31)^{*}\end{array}$ & $\begin{array}{c}\text { HBV } \\
n=10(5)\end{array}$ & $\begin{array}{l}\mathrm{HB}+\mathrm{C} \\
\mathrm{n}=4(2)\end{array}$ & $P$ value \\
\hline $\begin{array}{l}\text { Fever } \\
\text { Jaundice }\end{array}$ & $\begin{array}{l}7(6) \\
9(8)\end{array}$ & $\begin{array}{l}22(36) \\
19(31)\end{array}$ & $\begin{array}{l}4(40) \\
2(20)\end{array}$ & $\begin{array}{l}1(25) \\
2(50)\end{array}$ & \multirow[t]{5}{*}{$\begin{array}{c}*=0.0001 * 0.04 \\
*=0.032\end{array}$} \\
\hline ALT $<120$ & $10(8)$ & $16(26)$ & $2(20)$ & $2(50)$ & \\
\hline$A L T<200$ & $2(2)$ & $5(8)$ & $1(10)$ & $1(25)$ & \\
\hline AST $<120$ & $8(7)$ & $17(28)$ & $3(30)$ & $1(25)$ & \\
\hline AST $<200$ & $1(1)$ & $4(7)$ & $1(10)$ & $1(25)$ & \\
\hline Hepatotoxiciy & $8(7)$ & 20(33) & $3(30)$ & $3(75)$ & \multirow{2}{*}{$\begin{array}{l}{ }^{* *} 0.004 \\
\bullet \bullet 0.01 \\
\text { т } 0.03\end{array}$} \\
\hline Onset of hepatitis in days & $26-100[56.5]]^{* *} \nleftarrow \pi$ & $10-26[24.5]^{\star \star}$ & $12-16[17]$ & $10-29[21] \pi$ & \\
\hline Time to normalize in days & $7-17 \quad[10.5]$ & $15-31[22.5]$ & $14-39[31]$ & $18-32[21]$ & $\begin{array}{l}0.001 \\
0.02 \\
0.01\end{array}$ \\
\hline
\end{tabular}

ALT (U/L): Alanine Aminotransferase; AST (U/L): Aspartate Aminotransferase

Number between ( ) are percentage and between [ ] are average.

*The difference between control and HCV group.

-The difference between control and HBV group.

* The difference between control and $\mathrm{HB}+\mathrm{C}$ group.

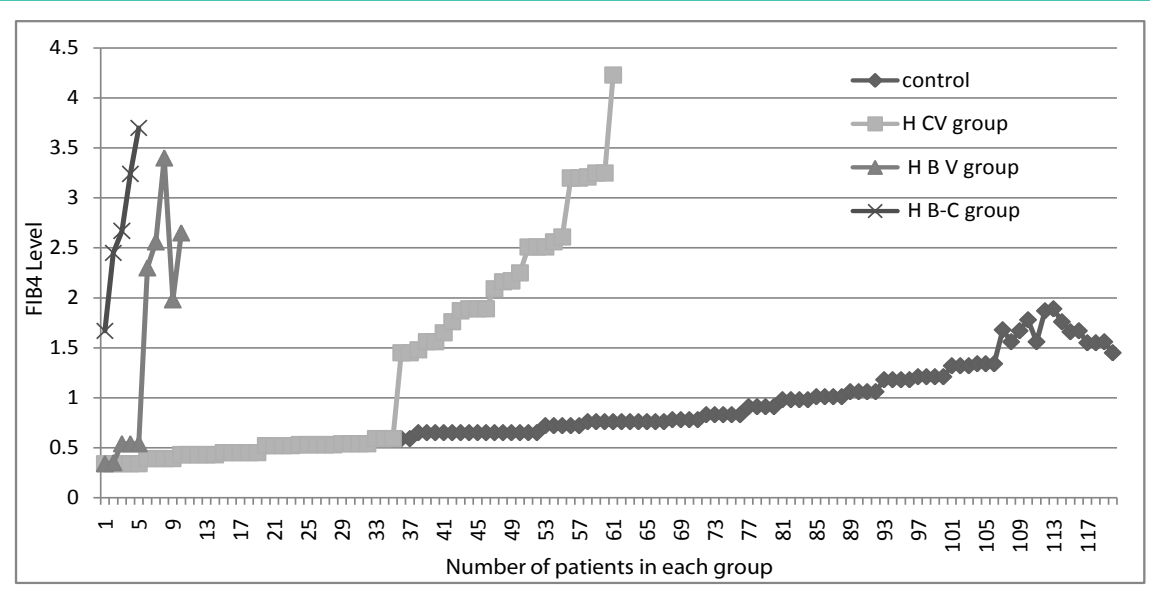

Figure 1: FIB4 level for control, hepatitis C (HCV) group and hepatitis B (HBV) group and hepatitis B and C (HB-C) group (vertical axis) and number of patients in each group (horizontal axis).

All the patients were HIV negative. Majority of our patients $(\mathrm{n}=120)$ were non infected with hepatitis $(62 \%)$ and considered as control for our study, while hepatitis $\mathrm{C}$ was diagnosed in 61 patients $(31 \%)$ and hepatitis B was seen in $5 \%(n=10)$ and infection by both hepatitis B and C was seen in $2 \%(n=4)$ patients. There were no significant differences among control group and hepatitis $\mathrm{C}$ and hepatitis B and hepatitis B and C groups as regards smoking or alcohol consumption (Table 1).

By measuring FIB4 according to this formula: FIB-4=Age (years) $\times \mathrm{AST}(\mathrm{U} / \mathrm{L}) /\left[\mathrm{PLT}\left(10^{9} / \mathrm{L}\right) \times \mathrm{ALT}^{1 / 2}(\mathrm{U} / \mathrm{L})\right]$, the fibrosis indices were $0.81,1.41,0.70,1.47$ at average for control, hepatitis $C, B, C \& B$ groups respectively with no statistically significant differences (Table $1)$.

After treatment, elevation of liver enzymes was noticed in all groups. Overall liver injury was seen in $17 \%(n=34)$ out of $195,7 \%$ of the control $(n=8)$ but $31 \%$ in the hepatitis $C$ group and in $30 \%$ in hepatitis B group and $75 \%$ in hepatitis B and $C$ group.

Liver fibrosis index FIB-4 was significantly increased after treatment in all groups but the difference was significant between control and (HCV) group ( $\mathrm{p}=0.04)$ although (HBV) group and (HBC) group showed increased of FIB4 index, the difference was not statistically significant (Table 2). The number of patients with FIB4 index above 1.45 was increased in all groups about $12 \%(\mathrm{n}=14)$ in control compared to $43 \%$ of (HCV) group ( $n=26), 50 \%$ of (HBV) group $(n=5)$ and $100 \%$ of $(\mathrm{HB}-\mathrm{C})$ group $(\mathrm{n}=4)$ (Figure 1).

FIB-4 scores has significantly increased among hepatitis groups compared to the control group, the number of controls who have FIB- $4>1.45$ has increased from $2 \%(n=3)$ to $14 \%(n=17)$ However in HCV group patients with FIB- $4>1.45$ have increased from $15 \%$ to $41 \%(n=25)$ with average score of 2.3 for HCV and 1.66 for control group $(\mathrm{p}<0.05)$ and for HBV group 50\% have increased FIB-4 score $(n=5)$ compared to $10 \%$ at the base line and average score for this $50 \%$ that are FIB- 4 score $>1.45$ was 2.6 and for HB-C group all the patients after treatment have FIB- 4 score $>1.45$ and average score was 2.75. The difference between control and HCV group was significant $(\mathrm{p}<0.05)$ (Table 3).

The onset of DILI was longest for the control group with average of 56.5 days compared to 24.5, 17 and 21 for HCV, HBV and HB-C 
Table 3: Liver fibrosis index FIB-4 scores before and after anti TB treatment.

\begin{tabular}{|c|c|c|c|c|c|}
\hline FIB-4 & $\begin{array}{c}\text { Control* }{ }^{* *} \\
* \star * \\
=120\end{array}$ & $\begin{array}{l}\mathrm{HCV}^{*} \\
\mathrm{n}=61\end{array}$ & $\begin{array}{c}\text { HBV ** } \\
n=10\end{array}$ & $\begin{array}{c}\mathrm{HB}+\mathrm{C} * * * \\
\mathrm{~N}=4\end{array}$ & $P$ value \\
\hline Number of pts Above 1.45 before TTT & 3 & 9 & 1 & 1 & \multirow{5}{*}{$\begin{array}{l}{ }^{*} 0.04 \\
{ }^{\star *} 0.3 \\
* * * .3\end{array}$} \\
\hline Range & $1.45-1.55$ & $1.45-1.65$ & 1.51 & 1.50 & \\
\hline Average & 1.48 & 1.49 & 1.51 & 1.50 & \\
\hline $\begin{array}{l}\text { Range after } \\
\text { TTT }\end{array}$ & $1.45-1.89$ & $1.45-4.23$ & $1.8-2.65$ & $1.6-3.7$ & \\
\hline Number of pts after TT & 17 & 25 & 5 & 4 & \\
\hline
\end{tabular}

TTT: Treatment

*The difference between control and HCV group.

**The difference between control and HBV group.

*** The difference between control and HB-C group.

groups and the differences were statistically significant.

None of either group has developed hepatic failure. The time for normalization was shorter for control compared to hepatitis C, $\mathrm{B}$ and HB-C groups. It was 10.5, 22.5, 31and 21 days for each group respectively $(\mathrm{P}>0.05)$ (Table 2$)$. During the period of hepatotoxicity, the offending drugs were replaced by non hepatotoxic drugs.

\section{Discussion}

Tuberculosis and viral hepatitis are still major health problems in Egypt. Although high percentages of TB cases are successfully treated, DILI in addition to concomitant viral hepatitis, both lead to significant morbidity that may decrease the effectiveness of drug therapy. In this study we looked at the hepatotoxic effect of anti tuberculous drugs in the presence of co infection with HBV, HCV or both viral infections.

Short-course chemotherapy containing rifampicin and isoniazid in combination has proved to be highly effective in the treatment of tuberculosis, but one of its adverse effects is DILI [19]. Anti-TB drugs are one of the commonest groups underlying idiosyncratic DILI worldwide [20,21].

The development of DILI during chemotherapy for TB is the most common reason leading to interruption of therapy [22]. Isoniazid and rifampicin given together produce DILI more frequently than either drug alone [23,24].

In our study the overall DILI was $17 \%$ (14\% hepatitis and $3 \%$ non hepatitis) compared to incidence of 5\%-28\% in other reports [20].

In another study, It was as low as $3.8 \%$ in cohort study of 3900 patients and only 150 had DILI but only 2 patients had hepatitis B surface Antigen positive [19], while in our study $76 \%$ DILI were seen in hepatitis co infection patients and $24 \%$ in non hepatitis infection. Recently the incidence of DILI has reduced to about $8 \%$ $10 \%$ in developing countries but it ranges from $1 \%-3.3 \%$ in Western countries [25].

The relatively higher incidence of hepatotoxicity in the developing countries may be explained by various factors such as older age, higher alcohol intake, malnutrition, intestinal parasitism, chronic liver disease, drug abuse, and high incidence of viral hepatitis [26].

In our study alcohol consumption was seen in $11 \%$ of patients and there was no difference among control and hepatitis patients. Intravenous drug abuse is a risk factor for transmission of hepatitis
B [27]. In our study IV drug abusers were seen in $30 \%$ of Hepatitis B and $25 \%$ in HB-C patients compared to $5 \%$ and $8 \%$ in hepatitis $\mathrm{C}$ and control group.

The reported risk factors for DILI are old age, female gender, poor nutritional status, high alcohol consumption, pre-existing liver disease, hepatitis $\mathrm{B}$ and $\mathrm{C}$ infections, extensive tuberculosis hypoalbuminemia $[28,29]$.

In our study average age was 35 years for both non hepatitis and hepatitis groups and males outnumber females. Base line liver enzymes were within normal range in all groups as well as liver Fibrosis scores (FIB4). Children were excluded from the study. They have different anti TB drugs dosages, in addition to the fact that DILI causative agent varies in children and in adults and the most common drugs that cause DILI in children are those acting on the central nervous system, antimicrobials and aspirin.

After treatment, DILI was $8 \%$ in control versus $33 \%$ in HCV and $30 \%$ in $\mathrm{HBV}$ and $75 \%$ in HB-C group and these results agreed with results of Ungo, et al. who studied the effect of hepatitis $\mathrm{C}$ infection in DILI and found that DILI was seen in $30 \%$ of HCV compared to $11 \%$ in non infected group and the risk of DILI was 5 folds in HCV patients than in control [30].

In another study DILI was $16 \%$ in $\mathrm{HBV}$ infected individuals compared to 4.7 non infected $(\mathrm{P}<0.001)$ [31].

In contrary to these results, Liu, et al. found that the incidence of DILI was similar in patients with and without chronic hepatitis $(8 \%$ vs. $7 \%, \mathrm{P}>0.05)$ [13].

In the current study, we measured liver fibrosis index which is a formula that is calculated based on patient age, level of ALT and AST and platelets level. Using a lower cutoff value of 1.45. FIB-4 score $<1.45$ had a negative predictive value of $90 \%$ for advanced fibrosis. In contrast, FIB- $4>3.25$ would have a $97 \%$ specificity and a positive predictive value of $65 \%$ for advanced fibrosis [32]. In our study the number of patients whose FIB-4 score were above 1.45 has increased in all groups including the control group but $\mathrm{HCV}$ group showed an increase from $15 \%$ to $41 \%$ compared to control group that increased from $2 \%$ to $17 \%$, also the FIB- 4 scores increase was more significant in $\mathrm{H} \mathrm{CV}$ group than in control group $\mathrm{p}<0.05$.

It was noticed after anti TB treatment that percentage of patients with high FIB4 scores were more than percentage of DILI based 
on the definition of elevated ALT and AST levels and this may be explained because the FIB-4 score includes age which is considered as an important independent risk factor for DILI and also platelets which is also an indicator for liver function.

The presence of significant fibrosis in chronic viral hepatitis indicates the need for antiviral therapies, and the outcome of therapy should be assessed by the improvement in fibrosis stage. FIB- 4 index is a simple, accurate, and inexpensive method for assessing liver fibrosis [33].

In a study by Fountain FF, et al. approximately $60 \%$ of the DILI incidence occurred in the first 3 months of treatment, and $80 \%$ of the incidence occurred in the first 6 months [34]. Another study showed that DILI has happened after 15-60 days from the date of commencing anti TB therapy [35]. Another study showed that the onset of DILI was not different among control and HBV and HCV which were 40, 39 and 67 days respectively all $\mathrm{P}>0.05$, in addition onset of DILI was most delayed in HCV which was 67 days and also this study showed that viral hepatitis does not increased risk of DILI [13]. In our study the average onset of DILI was longest in control group which was 56.5 days compared to $24.5,17$ and 21 days in HCV, HBV and $\mathrm{H}$ $\mathrm{B}-\mathrm{C}$ groups respectively and the differences were significant $\mathrm{P}<0.05$ ). The time to normalize liver function was longer in hepatitis patient compared to control 22.5, 31, 21 and 10.5 days for HCV, HBV, HB-C and control groups respectively. Our results are comparable with results of other investigator who found that the onset of DILI ranged from 13 days to 58 days (median, 26 days) after initiation of treatment [36]. And in another study, the median latent period for developing DILI was found to be 19 [10-25] days [37].

In summary, viral hepatitis increases the risk of development of DILI after commencement of hepatotoxic anti TB therapy and meticulous follow up of liver function is advised. Liver fibrosis index FBI is a promising tool for evaluation of liver damage and more studies are required to validate FIB-4 score value in predicting DILI.

\section{Acknowledgement}

I would like to thank our colleagues from Department of Clinical Pathology, Sohag University, especially Dr Laila M. Yousef for assistance and for expertise that greatly assisted the research and Dr Abeer Elkady from clinical pathology department, South Valley University, for comments that greatly improved the manuscript. I would also like to show my gratitude to Ms Azza Elkady, from microbiology and immunology department, Assiut University, for helping us during the course of this research in addition to our colleagues in hepatology department, Sohag University, for their fruitful information. All authors have no financial relations needed to be disclosed. This research received no specific grant from any funding agency.

\section{References}

1. World Health Organization. Global tuberculosis report 2015. Geneva: WHO 2015.

2. Lienard J, Carlsson F. Murine Mycobacterium marinum Infection as a Model for Tuberculosis. Methods Mol Biol. 2017; 1535: 301-315.

3. Tostmann A, Boeree MJ, Aarnoutse RE, de Lange WC, van der Ven AJ, Dekhuijzen R. Antituberculosis drug-induced hepatotoxicity: concise up-todate review. J Gastroenterol Hepatol. 2008; 23: 192-202.
4. Sharifzadeh M, Rasoulinejad M, Valipour F, Nouraie M, Vaziri S. Evaluation of patient-related factors associated with causality, preventability, predictability and severity of hepatotoxicity during antituberculosis [correction of antituberclosis] treatment. Pharmacol Res. 2005; 51: 353-358.

5. Singanayagam A, Sridhar S, Dhariwal J, Abdel-Aziz D, Munro K, Connell DW, et al. A comparison between two strategies for monitoring hepatic function during antituberculous therapy. Am J Respir Crit Care Med. 2012; 185: 653659.

6. Saukkonen JJ, Cohn DL, Jasmer RM, Schenker S, Jereb JA, Nolan CM, et al. An official ATS statement: hepatotoxicity of antituberculosis therapy. Am J Respir Crit Care Med. 2006; 174: 935-952.

7. Satyaraddi A, Velpandian T, Sharma SK, Vishnubhatla S, Sharma A, Sirohiwal A, et al. Correlation of plasma anti-tuberculosis drug levels with subsequent development of hepatotoxicity. Int J Tuberc Lung Dis. 2014; 18: 188-195.

8. Fernández-Villar A, Sopeña B, Fernández-Villar J, Vázquez-Gallardo R, Ulloa $F$, Leiro $V$, et al. The influence of risk factors on the severity of antituberculosis drug-induced hepatotoxicity. Int J Tuberc Lung Dis. 2004; 8: 1499-1505.

9. Shepard CW, Finelli L, Alter MJ. Global epidemiology of hepatitis C virus infection. Lancet Infect Dis. 2005; 5: 558-567.

10. Gower E, Estes C, Blach S, Razavi-Shearer K, Razavi H. Global epidemiology and genotype distribution of the hepatitis C virus infection. J Hepatol. 2014; 61: S45-S57.

11. Daniel Lavanchy, Mark Kane. Global Epidemiology of Hepatitis B Virus Infection. Chapter Hepatitis B Virus in Human Diseases. 2016; 187-203.

12. Devarbhavi H, Singh R, Patil M, Sheth K, Adarsh CK, Balaraju G. Outcome and determinants of mortality in 269 patients with combination anti-tuberculosis drug-induced liver injury. J Gastroenterol Hepatol. 2013; 28: 161-167.

13. Liu YM, Cheng YJ, Li YL, Liu CE, Hsu WH. Antituberculosis treatment and hepatotoxicity in patients with chronic viral hepatitis. Lung. 2014; 192: 205210.

14. Parsons LM, Somoskövi A, Gutierrez C, Lee E, Paramasivan CN, Abimiku A, et al. Laboratory diagnosis of tuberculosis in resource-poor countries: challenges and opportunities. Clin Microbiol Rev. 2011; 24: 314-350.

15. Tukvadze N, Kempker RR, Kalandadze I, Kurbatova E, Leonard MK, Apsindzelashvili $\mathrm{R}$, et al. Use of a molecular diagnostic test in AFB smear positive tuberculosis suspects greatly reduces time to detection of multidrug resistant tuberculosis. PLoS One. 2012; 7: e31563.

16. http://www.who.int/tb/publications/2010/9789241547833/en/

17. http://www.hepatitisc.uw.edu/page/clinical-calculators/fib-4

18. https://www.thecalculator.co/health/Fibrosis-4-(FIB-4)-Score-Calculator-702. html

19. Gaude GS, Chaudhury A, Hattiholi J. Drug-induced hepatitis and the risk factors for liver injury in pulmonary tuberculosis patients. J Family Med Prim Care. 2015; 4: 238-243.

20. Ostapowicz G, Fontana RJ, Schiødt FV, Larson A, Davern TJ, Han SH, et al. Results of a prospective study of acute liver failure at 17 tertiary care centers in the United States. Ann Intern Med. 2002; 137: 947-954.

21. Devarbhavi H, Dierkhising R, Kremers WK. Antituberculosis therapy druginduced liver injury and acute liver failure. Hepatology. 2010; 52: 798-799.

22. Schaberg T, Rebhan K, Lode H. Risk factors for side-effects of isoniazid, rifampin and pyrazinamide in patients hospitalized for pulmonary tuberculosis. Eur Respir J. 1996; 9: 2026-2030.

23. Snider DE Jr, Long MW, Cross FS, Farer LS. Six-months isoniazid-rifampin therapy for pulmonary tuberculosis. Report of a United States Public Health Service Cooperative Trial. Am Rev Respir Dis. 1984; 129: 573-579.

24. Tsagaropoulou-Stinga $H$, Mataki-Emmanouilidon $T$, KaridaKavalioti $S$ Manios S. Hepatotoxic reactions in children with severe tuberculosis treated with isoniazid, rifampicin. Pediatr Infect Dis. 1985; 4: 270-273. 
25. Tost JR, Vidal R, Cayla J, Diaz-Cabanela D, Jimenez A, Broquetas JM. Severe hepatotoxicity due to anti-tuberculosis drugs in Spain. The International Journal of Tuberculosis and Lung Disease. 2005; 1; 9: 534-540.

26. Gangadharam PR. Isoniazid, rifampin, and hepatotoxicity. Am Rev Respir Dis. 1986; 133: 963-965.

27. Seal KH, Edlin BR, Ochoa KC, Tulsky JP, Moss AR, Hahn JA. Risk of hepatitis $B$ infection among young injection drug users in San Francisco: opportunities for intervention. West J Med. 2000; 172: 16-20.

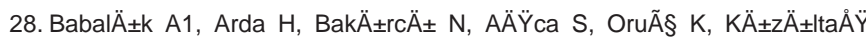
$\mathrm{S}$, et al. Management of and risk factors related to hepatotoxicity during tuberculosis treatment. Tuberk Toraks. 2012; 60: 136-144.

29. Saukkonen JJ, Cohn DL, Jasmer RM, Schenker S, Jereb JA, Nolan CM, et al. An official ATS statement: hepatotoxicity of antituberculosis therapy. Am J Respir Crit Care Med. 2006; 174: 935-952.

30. Ungo JR, Jones D, Ashkin D, Hollender E, Bernstein D, Albanese A, et al Antituberculosis drug-induced hepatotoxicity: the role of hepatitis $\mathrm{C}$ virus and the human immunodeficiency virus. Am J Respir Crit Care Med. 1998; 157: 1871-1876.

31. Wang JY, Liu CH, Hu FC, Chang HC, Liu JL, Chen JM, et al. Risk factors of hepatitis during anti-tuberculous treatment and implications of hepatitis virus load. J Infect. 2011; 62: 448-455.
32. Sterling RK, Lissen E, Clumeck N, Sol R, Correa MC, Montaner J, et al. Development of a simple noninvasive index to predict significant fibrosis in patients with HIV/HCV coinfection. Hepatology. 2006; 43: 1317-1325.

33. Vallet-Pichard A, Mallet V, Nalpas B, Verkarre V, Nalpas A, Dhalluin-Venier V, et al. FIB-4: an inexpensive and accurate marker of fibrosis in HCV infection. comparison with liver biopsy and fibrotest. Hepatology. 2007; 46: 32-36.

34. Fountain FF, Tolley E, Chrisman CR, Self TH. Isoniazid hepatotoxicity associated with treatment of latent tuberculosis infection: a 7-year evaluation from a public health tuberculosis clinic. Chest. 2005; 128: 116-123.

35. Makhlouf H, Makhlouf N, Metwally M, Rashed HA. Double impact: Difficulties in treating patients with liver diseases from tuberculosis. European Respiratory Journal. 2011; 38: 4895.

36. Abera W, Cheneke W, Abebe G. Incidence of antituberculosis-drug-induced hepatotoxicity and associated risk factors among tuberculosis patients in Dawro Zone, South Ethiopia: A cohort study. Int J Mycobacteriol. 2016; 5 : 14-20.

37. El Bouazzi O, Hammi S, Bourkadi JE, Tebaa A, Tanani DS, Bencheikh RS, et al. First line anti-tuberculosis induced hepatotoxicity: incidence and risk factors. Pan Afr Med J. 2016; 25: 167.
Austin J Gastroenterol - Volume 4 Issue 3 - 2017

ISSN : 2381-9219 | www.austinpublishing group.com

Alkady et al. (@) All rights are reserved
Citation: Alkady OA, Yousef LY, Elkady AA and Elkady AA. Evaluation of Drug Induced Liver Injury in Tuberculosis and Hepatitis Coinfection by Liver Fibrosis Index Score. Austin J Gastroenterol. 2017; 4(3): 1086. 